\title{
TELEJORNALISMO REGIONAL E TELEVISÃO UNIVERSITÁRIA: UNIDOS PELO VIVER JUNTO NA CONSTRUÇÃO DA NOTÍCIA
}

\author{
REGIONAL TELEVISION NEWS AND UNIVERSITY TELEVISION CHANNELS, \\ UNITED BY LIVING TOGETHER IN BUILDING THE NEWS
}

TELEPERIODISMO REGIONAL Y LA TELEVISIÓN UNIVERSITARIA, UNIDOS POR LA CONVIVENCIA EN LA CONSTRUCCIÓN DE LA NOTICIA

\author{
Paula Puhl \\ Dra, PUCRS \\ papuhl@terracom.br
}

\begin{abstract}
Resumo: $\mathrm{O}$ artigo discute as aproximações entre o telejornalismo regional e as televisões universitárias, compreendidas como mediadoras dos principais assuntos ocorridos na comunidade da qual elas fazem parte. Para proceder à análise, leva-se em consideração a proximidade entre fonte e repórter na apuração e na apresentação da notícia na TV, a partir das ideias sobre o viver junto de Barthes (2003). O objeto desse estudo é a TV Feevale, que pertence à universidade de mesmo nome, tendo como recorte o seu telejornal diário, o TV Feevale Notícias, por intermédio de uma pesquisa baseada em dados quantitativos e qualitativos. Foi verificado que o telejornal universitário é a única fonte de notícias da região veiculada na televisão. O repórter, por sua vez, tem papel de agente e mediador das questões da comunidade em função da sua proximidade das fontes.
\end{abstract}

Palavras-chave: telejornalismo regional; televisão universitária; repórter; fonte

\begin{abstract}
The article discusses the similarities between the regional television news and academic television channels, understood as mediators of the main issues occurring in the community of which they are part. To perform the analysis the proximity between source and reporter in the reporting and presentation of the news on $\mathrm{TV}$, from the ideas about living together by Barthes (2003) are considered. The object of this study is TV Feevale, which belongs to the university of the same name, focusing on the daily newscast TV Feevale Noticias through a survey based on qualitative and quantitative data. It was found that the university is the only television news source from the region on air. The reporter has the role of agent and mediator of community issues through its proximity to sources.
\end{abstract}

Keywords: regional television news, university television, reporter, source

Resumen: El artículo analiza las similitudes entre las noticias del teleperiodismo regional y las televisiones universitarias entendidas como mediadoras de los principales problemas que ocurren en la comunidad que pertenecen. Para realizar el análisis se considera la proximidad entre la fuente y periodista en la investigación y en la presentación de las noticias en la televisión, de las ideas sobre la convivencia de Barthes (2003). El objeto de este estudio es la Feevale TV, que pertenece a la universidad del mismo nombre, enfocando su TV Feevale Notícias, un noticiero diario por una investigación basada en datos cuantitativos y cualitativos. Se encontró que el teleperiodico es la única fuente de noticias de la región que se emitió en la televisión. El periodista, a su vez, tiene la función de agente y mediador de asuntos de la comunidad a través de su proximidad con las fuentes.

Palabras clave: teleperiodismo regional, televisiones universitarias, periodista, fuentes

Esta obra está licenciada sob uma Licença Creative Commons 


\section{INTRODUÇÃO: O CONTEXTO DO ESTUDO}

No Jornalismo é vista a incessante busca pela credibilidade que está em constante batalha com a informação mais rápida, quase em tempo real. Essa guerra desigual exige um jornalista mais prático, rápido e atento. Porém, cada vez menos ele vai até as suas fontes. Ele é sedento somente pelas suas "breves" palavras e não pela sua história ou pela sua representatividade na sociedade. Esse comportamento do repórter pode vir a prejudicar o aprofundamento e contextualização da informação.

Essas transformações contemporâneas nos levam a repensar a prática jornalística e o lugar estabelecido para a relação entre fonte e repórter. Enquanto as grandes empresas jornalísticas sustentam a rapidez, a quantidade de matérias veiculadas, a quase onipresença dos jornalistas na cobertura dos acontecimentos, nesse artigo a proposta é apresentar uma situação diferente. O objetivo é verificar a importância do fazer jornalístico voltado à região no meio televisivo e a atenção destinada às fontes. Nosso objeto é a TV Feevale, televisão universitária que pertence à universidade de mesmo nome localizada na cidade de Novo Hamburgo, no Rio Grande do Sul. A justificativa da escolha desse objeto está relacionada às características da produção telejornalística do canal e à sua importância para a região.

O recorte do objeto será o TV Feevale Notícias, o telejornal diário que apresenta tanto notícias da instituição de ensino (IES) quanto as notícias da comunidade de Novo Hamburgo. Serão escolhidas reportagens específicas para verificar de que forma são produzidas as notícias quando existe uma aproximação entre o repórter e suas fontes. Para isso o apoio teórico serão as ideias de Roland Barthes apresentadas na obra Como viver junto (2003). O livro apresenta os cursos e os seminários que Barthes lecionou no Collège de France, datados de 1976 - 1977. O material produzido pelo autor tem como objetivo explorar um imaginário em particular - as formas de como "viver junto" de grupos restritos em que a vida cotidiana do sujeito ou do grupo está ligada a um espaço típico. Justificamos a escolha de Barthes, pois o mesmo descreve a linguagem como o próprio lugar da sociabilidade, onde o poder é exercido pelas palavras e pela utopia em minimizar as diferenças entre os sujeitos, buscando o viver junto.

Por acreditar que o jornalismo está ancorado na linguagem e tem o intuito de colaborar com esse "viver junto", pretendemos verificar de que forma ocorre esse viver junto na relação entre repórter e fonte, já que a comunidade necessita que a sua fala seja divulgada pelo repórter para que o seu discurso seja legitimado, enquanto que o repórter 
precisa de uma boa história apoiada em fatos para ter a credibilidade da opinião pública. Assim, instala-se um processo de interdependência entre os sujeitos. E é nesse limiar entre legitimidade e credibilidade entre ambos que acreditamos que o envolvimento é o fator diferencial na busca dos fatos que compõem a notícia, pois através da exposição das emoções dizemos o que realmente pensamos, mas, por outro lado, questiona-se se o Jornalismo aceita o fato de que a expressão dos sentimentos e o "envolvimento" com a fonte podem tornar-se aliadas na apuração das informações.

Verificar esse processo de interdependência entre fonte e repórter por intermédio do viver junto e da presença do sentimento para a busca da informação, principalmente em televisões universitárias, onde as notícias são pautadas pela comunidade, é o lugar em que estão situadas as questões que irão nortear o estudo pretendido neste artigo.

Este estudo faz parte de um projeto maior intitulado, "A construção das identidades

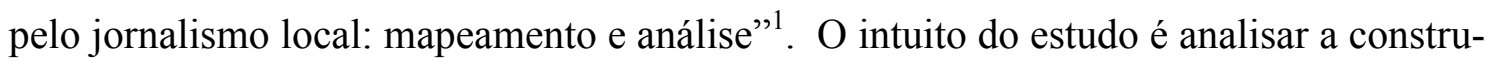
ção das identidades dos moradores da cidade de Novo Hamburgo (RS) através do telejornalismo local. Ou seja, este estudo, ao mesmo tempo em que tem como foco o local, pode ser verificado em outras localidades que tenham características e contextos próximos da cidade de Novo Hamburgo.

\section{O TELEJORNALISMO REGIONAL E AS TVS UNIVERSITÁRIAS}

No telejornalismo regional, conseguimos visualizar com mais facilidade essa proximidade do repórter com o local de forma mais natural, pois muitas vezes é a mesma equipe que faz a cobertura dos assuntos importantes dessa comunidade, o que acaba levando-a a se envolver emocionalmente com as fontes. Em outras palavras, em veículos cuja pauta está mais concentrada na comunidade, de uma forma ou outra as fontes acabam sendo repetidas e se tornando conhecidas dos repórteres, assim como a equipe de reportagem, ao dar voz ao cidadão, recebe legitimidade por parte dele quando este vê na televisão suas reclamações e sua imagem.

O investimento em um telejornalismo regional hoje é percebido na grade de programação tanto das televisões abertas quanto fechadas. Silva (2005) destaca que a regionalização da programação ainda é uma tendência de mercado, já que as grandes redes

\footnotetext{
${ }^{1}$ O projeto fomentado pela Fapergs e Cnpq (2011-2014) e contou com dois bolsistas - Aline Streck Donato ( mestrado) e Jeferson Saldanha Ramos (graduação) na coleta e organização dos dados, durante os anos de 2011 e 2012. O artigo foi desenvolvido quando a pesquisadora estava desenvolvendo atividades na Universidade Feevale até 2013.
} 
não conseguem atender as demandas das diversas regiões. Com isso, as redes mantêm o foco na produção jornalística nas capitais, e os telejornais regionais possuem forte participação no cenário televisivo nacional devido seu direcionamento editorial que apresenta uma realidade próxima de seus telespectadores. Os telejornais passam a ser mais valorizados, permitindo uma aproximação com o público. "O local oferece uma resposta que privilegia a diversidade, as diferenças, a multiplicidade das escalas e a força das pequenas unidades" (BOURDIN, 2001, p. 29).

Esse cenário faz parte da cidade de Novo Hamburgo, distante $40 \mathrm{~km}$ de Porto Alegre, capital do estado do Rio Grande do Sul. A cidade não possui um telejornal em televisão aberta, diferentemente de outras cidades do estado que possuem um tempo destinado para a sua região dentro do telejornal da RBS, sucursal da Rede Globo no Rio Grande do Sul. Por esse motivo, a TV Feevale em 2008 cria o TV Feevale Notícias, telejornal diário com 30 minutos de duração para fazer cobertura dos fatos noticiosos do município.

Para Bazi (2001, p. 12) "o desafio será conciliar a programação local com qualidade e conseguir sustentar os altos custos que isso acarreta". A TV regional tem a responsabilidade de fornecer ao telespectador uma programação local que ajude a pensar globalmente, ela deve desenvolver conceitos e textos que expliquem as ligações entre as comunidades locais e os sistemas mais amplos.

Apoiado nas ideias de Bazi (2001), que define televisão regional como a que retransmite seu sinal a uma região pré-definida com programação voltada para a mesma, concordamos que a TV regional deve servir para desenvolver as características culturais de cada comunidade. Dessa forma, combate-se uma homogeneização que poderia ser causada pelas grandes redes de comunicação.

Bergesch (2010, p. 233) acredita que o surgimento de uma televisão em determinada região traz junto a tendência de "voltar-se ao cosmopolitismo, exigido pelas características do próprio meio de comunicação de massa, pelas peculiaridades determinadas pelos conteúdos, pelos custos e pela generalização dos interesses coletivos”. Em sua análise sobre a regionalização da TV no Rio Grande do Sul, Bergesch (2010) avalia que a condição local é a particularidade que define a história do meio no sul do país. Ele destaca que no Rio Grande do Sul sempre houve uma diferença: a exigência e espera do público por programas construídos localmente, que se identificassem com a comunidade. 
Bazi (2001) afirma que no espaço regional não existe uma definição de limites precisos, mas um lugar específico no qual a população dessa região se sente inserida e partilha de sentidos, cujos espaços lhes são familiares. Nesses espaços, as identidades são moldadas a partir das vivências diárias dessas pessoas. Diante disso, o local ganha uma valorização no conjunto da sociedade e pode ser observado inclusive nos meios de comunicação de massa, como a TV, que historicamente sempre preferiu temas globais por atingir um maior número de pessoas. Um instrumento para isso pode ser o noticiário, que dentro das suas extensões regionais influencia o sujeito na construção da própria imagem, sugerindo comportamentos e suscitando reflexões, além de produzir um efeito de diversidade, reproduzindo a dinâmica da vida e causando um efeito de pertencimento e familiaridade de um território específico, acredita Bazi (2001).

Essas ideias sobre a televisão regional encontram espaço nas televisões universitárias, que, por estarem ligadas a uma instituição de ensino, possuem abrangência muitas vezes delimitada, mas acabam por representar a comunidade do local. Dessa forma é importante saber mais sobre a função e a consolidação das TVs universitárias no país e também apresentar o nosso objeto de estudo, a TV Feevale, no item a seguir.

\subsection{A TV universitária no Brasil e a TV Feevale}

As televisões universitárias ganham relevância após a promulgação da lei federal 8977, de 5 de janeiro de 1995, conhecida como a "Lei do Cabo". No artigo 23, instituise o chamado "Canal Básico de Utilização Gratuita", que expõe o que as operadoras de TV paga são obrigadas a disponibilizar sem custos para seus assinantes. Entre eles, especifica-se "um canal universitário, reservado para o uso compartilhado entre as universidades localizadas no município ou municípios da área de prestação do serviço".

Em 30 de outubro de 2000, em São Paulo, um grupo de IES funda a ABTU Associação Brasileira de Televisão Universitária. Em 2004, através de pesquisa realizada pela UNESCO, onde se viabilizava traçar uma espécie de mapa da TV Universitária no país, contabilizava-se mais de trinta canais de cabodifusão mantidos por sessenta e quatro Instituições de Ensino Superior, sendo onze canais compartilhados por várias Universidades e vinte canais exclusivos, ou seja, ocupados por apenas uma Instituição de Ensino Superior.

Portanto, a quantidade de IES envolvidas, a variedade das propostas de programação e a multiplicidade dos sistemas técnicos utilizados para a transmissão dos sinais são indicadores da expansão da Televisão universitária no país. Assim, a universidade 
brasileira vai deixando para trás antigos preconceitos contra a televisão e passa a confiar no potencial dessa mídia para a difusão de informação, cultura, educação e cidadania.

A televisão universitária deve servir, assim como os demais núcleos acadêmicos, para a experimentação, mas sem amadorismo. Dessa maneira, a proposta de linguagens e o uso dos formatos tradicionais em prol do desenvolvimento da sociedade e da cidadania e a visão da Academia são mais uma alternativa de programação televisiva para o telespectador brasileiro.

De acordo com Ramalho (2010), as TVs universitárias, individualmente, produzem uma média de 6 horas inéditas semanais, dentro de um espectro que vai desde 1 hora até 21 horas/semana, e, na grande maioria, o quadro de funcionários se dá a partir de estagiários e professores. De acordo com a ABTU, as televisões universitárias produzem cerca de 240 horas/semana no país de programas inéditos. Assim, percebe-se que a transmissão é determinante, já que as emissoras universitárias transitam entre as abertas (13h20min) e as a cabo (2h50min). Quanto à produção, o segmento se mostra independente. A maioria, cerca de 70\% das TVs Universitárias, tem como única produção a que sai de seus estúdios e ilhas de edição (Ramalho, 2010).

Para Magalhães (2002, p. 51), por meio da TV universitária, “é possível compartilhar conhecimentos com a sociedade, estabelecer um elo com as suas comunidades, acadêmica e social; é o lugar em comum e não o lugar comum". O telejornalismo também está presente, principalmente, mas não unicamente, nas emissoras abertas. A ABTU afirma que cerca de $18 \%$ das TVs Universitárias já se aventuram no telejornalismo diário, enfrentando os altos custos de sua produção e a concorrência das emissoras tradicionais.

Por isso, aliado aos próprios objetivos culturais e educativos das IES, o telejornalismo universitário busca um formato de reportagens diferenciado, privilegiando a informação que esclareça com mais profundidade e oriente os seus telespectadores na formação de um pensamento critico.

\subsection{A TV Feevale}

A TV Feevale foi fundada no ano de 2002 pela Universidade Feevale da cidade de Novo Hamburgo/ RS. Começa suas transmissões pelo canal 15 da NET, apoiada pela 
Lei do $\mathrm{Cabo}^{2}$, que dá a possibilidade de transmitir a programação de sua TV universitária para a localidade de Novo Hamburgo.

Mas é a partir do ano de 2007 que a TV Feevale deixa de lado seu caráter unicamente acadêmico de transmitir produções dos alunos da Universidade Feevale e passa a ter um desígnio mais profissional, com a produção voltada para a comunidade.

A TV Feevale, nesse aspecto, por ser universitária e possuir um vínculo direto com o grupo social, tem comprometimento com o interesse público, considerando o telespectador como um cidadão e não apenas como um consumidor de notícias como outro qualquer. Além disso, também possui algumas vantagens em matéria de conteúdo e veiculação que não são permitidas em emissoras privadas. A linha editorial é diferenciada da dos outros canais informativos veiculados na região - todos eles particulares -, pois a TV Feevale tem a possibilidade de produzir e veicular a notícia em um tempo consideravelmente maior.

Bazi (2001, p. 63) alega que a conquista da audiência de uma emissora regional passa, necessariamente, pela questão da qualidade de seus programas e da sua credibilidade junto ao público. A TV Feevale se preocupa em atingir e alcançar visibilidade na região de Novo Hamburgo e, por esse motivo, busca sempre focar suas produções nos interesses dessa comunidade.

Rodrigo Teixeira (2011), jornalista e coordenador da TV, ressalta que a TV Feevale tem como dever mostrar as notícias de Novo Hamburgo, não sendo eficiente para a emissora a veiculação de notícias de outras localidades. De acordo com ele, "hoje,

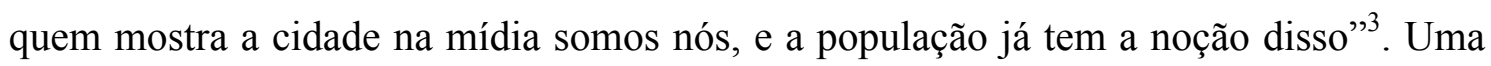
das formas de alcançar tal intento, segundo o responsável pela TV Feevale, é trazer assuntos nacionais para o cotidiano de Novo Hamburgo, utilizando fontes da própria localidade.

A emissora ainda não realizou uma pesquisa de audiência, mas os responsáveis garantem que a aproximação com a população hamburguense rendeu frutos, como relata Teixeira: "no início da TV, nós os procurávamos muito mais do que eles nos procuravam, hoje ocorre o inverso". Prova de tal afirmativa, ainda segundo ele, pode ser medida pela quantidade de e-mails e ligações que a TV Feevale recebe diariamente dos telespectadores com comentários e sugestões - cerca de 15.

\footnotetext{
${ }^{2}$ Lei $n^{\circ} 8.977$ de 6 de janeiro de 1995. Deu oportunidade para que os distribuidores de sinais de TV aberta optassem por transformar sua outorga em concessão de TV a Cabo. As licenças têm caráter local, limitadas a um município. ${ }^{3}$ Entrevista concedida em 2011 a bolsistas do projeto Aline Streck Donato (ver nas referências).
} 
Outra característica importante da TV Feevale está na escolha de suas pautas. Por não ter compromisso com a factualidade, a emissora aborda temas culturais que não têm espaço nas emissoras privadas. A TV Feevale divulga ações e fatos recorrentes na cidade, sendo eles cotidianos ou não, como expõe Teixeira: "quando Novo Hamburgo aparece em outras emissoras é porque algo ruim aconteceu na cidade. Elas têm pouco espaço e priorizam, assim, acontecimentos da Capital ou tragédias. Aqui o telespectador tem a possibilidade de enxergar as coisas boas da região e com um tempo melhor".

Atualmente, nove programas são produzidos pela TV Feevale. Entre eles está o Feevale Notícias, foco desse artigo para a análise das relações do repórter com a fonte em âmbito regional. Caracerizado por ser telejornal diário (de segunda a sexta) e ao vivo (das 18h:30 as 19h), o programa destaca as principais notícias da Universidade Feevale e da cidade de Novo Hamburgo, com o apoio da população.

\subsection{Análise do TV Feevale Notícias a partir da relação repórter e fonte}

Antes de apresentar o recorte do nosso objeto, o TV Feevale Notícias, é importante esclarecer como entendemos os critérios de noticiabilidade e o papel do repórter. O conjunto de elementos que definem a noticiabilidade do acontecimento estão relacionados, conforme refere-se Vizeu (2005), aos processos rotineiros das práticas produtivas das redações, considerando os valores/notícia que definem os acontecimentos que são interessantes, significativos e relevantes para serem transformados em notícia. Segundo o autor, são as diferentes relações e combinações que se dão entre os diferentes valores/notícia que são os fatores determinantes na seleção de um fato.

Dessa forma, o repórter é visto como o responsável em conduzir a notícia. Ele é o agente da mensagem. O público ainda considera como uma boa matéria aquela em que o repórter está no local, confrontando diferentes posicionamentos e apresentando versões que permitem a melhor orientação do espectador.

Lage (2001) sempre defendeu a ideia de que o repórter deve estar onde o seu público não pode estar e acrescenta também a importância do repórter estar inserido no ambiente que compreenderá a sua narrativa. Esse processo produtivo diferencia uma reportagem viva de um relato construído. Além dessas características para compor uma reportagem, o repórter necessita de fontes para confrontar versões, buscando a verdade mais próxima da realidade. 
As ideias de Vizeu (2005) e Lage (2001) são percebidas no TV Feevale Notícias, assim como as características de telejornalismo regional descritas principalmente por Bazi (2001). O telejornal iniciou suas atividades em 2008 e desde a sua criação o objetivo, segundo Teixeira (2011), foi aproximar o canal da comunidade e tentar mesclar as notícias da região com as pautas institucionais. Para verificar essa aproximação, foi escolhido para a análise o período de 27 de junho a 01 de julho de 2011. Ao todo, foram assistidas cinco edições do telejornal. As matérias, em um primeiro momento, foram classificadas e ordenadas a partir do seu formato de apresentação e definidas por nota pelada, nota coberta ou reportagem. Foram escolhidas apenas as reportagens, por julgar que nesse formato existe a troca de uma espécie de "olhar", entre repórter e fonte, a partir da troca sonora.

Outro critério para a escolha das matérias está vinculado aos temas que estão divididos em: matérias institucionais; matérias que dão importância aos acontecimentos da própria IES; e matérias comunitárias, por manterem a relação da notícia com o cidadão de Novo Hamburgo. Após a escolha, será feita a análise nas reportagens de cunho comunitário, com foco nas falas tanto do repórter quanto da fonte.

Cada edição do TV Feevale Notícias tem a duração de trinta minutos. Na semana de análise foram veiculadas 41 matérias, sendo que 10 tinham foco institucional e 31 abordavam assuntos ocorridos na comunidade hamburguense. Assim, podemos afirmar que na semana escolhida, $24 \%$ das matérias do telejornal eram Institucionais e $76 \%$, comunitárias:

Gráfico 1: Temas das matérias do TV Feevale Noticias

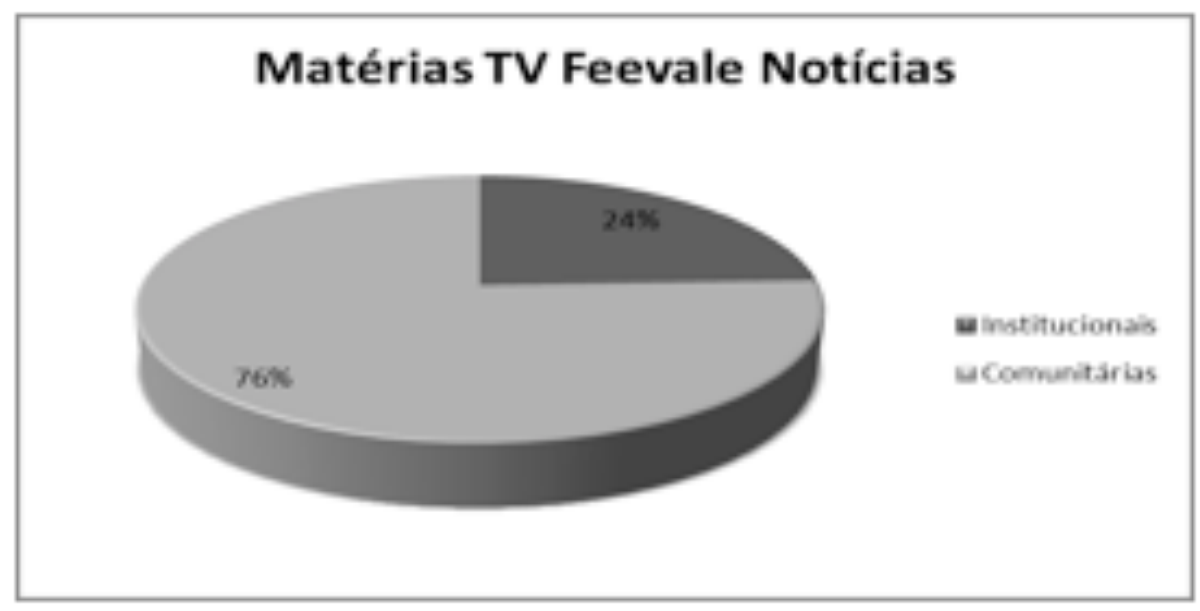

Fonte: Autora ( 2013)

Dessas 31 matérias geradas pelos acontecimentos junto à comunidade, 16 seguiram o formato de reportagem, representando $56 \%$. As outras matérias foram apresenta- 
das da seguinte forma: 8 notas peladas (26\%), 2 notas cobertas $(6 \%)$ e 5 entrevistas apresentadas sempre ao final de cada edição do telejornal $(6 \%)$, conforme o gráfíco abaixo:

Gráfico 2: Tipos das matérias do TV Feevale Notícias

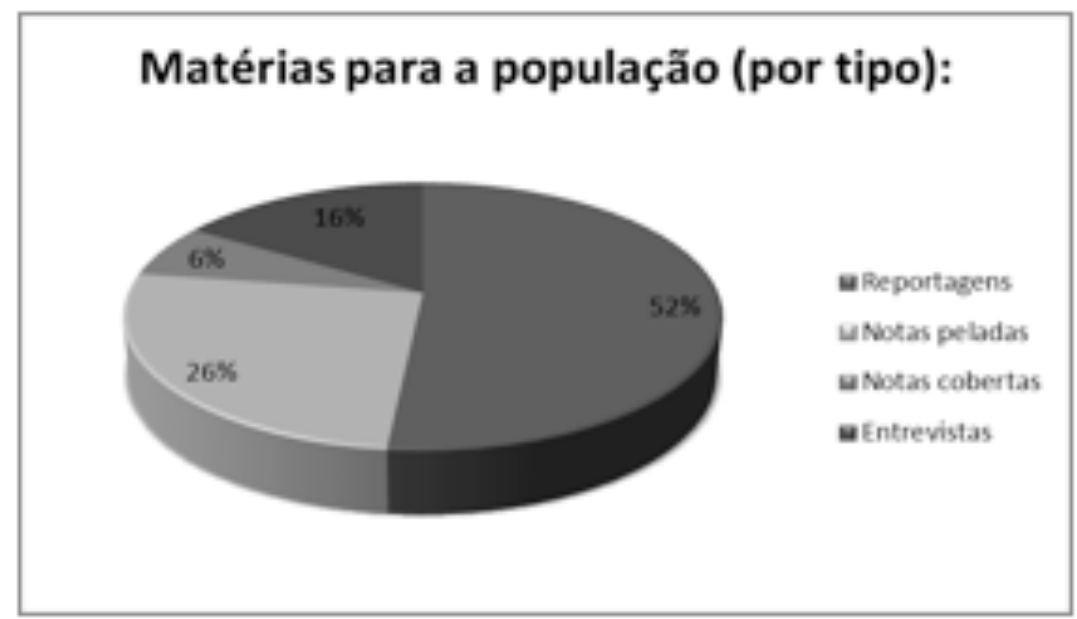

Fonte: autora (2013)

As 16 reportagens produzidas junto à comunidade representaram 57 minutos das $2 \mathrm{~h} 30$ totais da veiculação semanal do telejornal, representando um percentual de $38 \%$ das notícias veiculadas. Os temas foram organizados pelos títulos das matérias, que contemplaram as seguintes editorias: saúde, obras e infraestrutura, cultura e entretenimento, política, economia, esporte, geral, polícia e educação.

A partir dessa análise quantitativa, percebemos que o telejornal diário da TV Feevale é visto como um meio que permite à comunidade tanto mostrar e dar visibilidade aos seus problemas como receber respostas das autoridades responsáveis via o telejornal, ou seja, a televisão colabora como um lugar de pertencimento dos cidadãos hamburguenses.

\section{$2.4 \mathrm{O}$ viver junto pelo telejornalismo na relação repórter e fonte}

No decorrer do texto foi verificado que a TV Feevale, mesmo sendo uma televisão universitária, está ligada ao conceito de telejornalismo regional. Essa constatação foi feita a partir da observação dos assuntos que fazem parte da sua grade de programação, que privilegia os assuntos da região. É importante lembrar que a cidade não possui um telejornal específico sobre ela em TV aberta, já que a RBS, sucursal da Rede Globo transmite para Novo Hamburgo o telejornal feito com o foco na capital Porto Alegre. 
Assim, cabe ao TV Feevale Notícias abordar os acontecimentos do local, e, por essa razão, ele acaba por necessitar ter mais proximidade com a população.

Nesse sentido, nas reportagens - ao todo foram 16 com temática voltada à comunidade -, notamos por intermédio das falas dos repórteres um tratamento diferenciado em relação às fontes. Dois aspectos se destacaram: o tempo destinado à fala da comunidade excede os 20 segundos usuais do telejornalismo tradicional juntamente com o tom que acompanham esses depoimentos, e a preocupação da equipe em retornar ao local para verificar se o problema apresentado foi solucionado pelos órgãos competentes.

Por esses motivos, notou-se uma espécie de jornalismo diferenciado, que fica no limiar entre a apuração dos fatos e o envolvimento do repórter. Dessa forma, consideram-se pertinentes as ideias de Puhl (2010) sobre o jornalismo afetivo, apoiada no conceito de Barthes (2003) sobre o viver junto a partir da linguagem, que para o autor é o lugar da sociabilidade, onde o poder é exercido pelas palavras e pela utopia em minimizar as diferenças entre sujeitos, buscando, assim, o viver junto. Puhl (2010), por sua vez, adaptou esse conceito na relação entre repórter e fonte, já que a linguagem os une pelas diferenças, pela disputa de forças de poder que ambos possuem, ou seja, a autora acredita que um precisa do outro para ter uma existência social legítima. Dessa forma, é instalado um processo de interdependência dos sujeitos e é nesse limiar entre a legitimidade (desejo da fonte) e a credibilidade (desejo do repórter) que se acredita que o afeto pode ser um fator diferencial na apuração da notícia.

Para exemplificar essas falas em prol do "viver junto", serão apresentadas duas reportagens que tiveram seguimento durante a semana em que o foco de observação era a editoria Obras e Infraestrutura ${ }^{4}$.

A primeira reportagem, de seis minutos, exibida no dia 30 de junho de 2011, produzida pela acadêmica de Jornalismo Joceline Silveira, notamos um tom de denúncia desde a apresentação da matéria pedindo socorro dos moradores do bairro Alpes do Vale. O tema são os problemas do acesso principal ao bairro - interrompido desde abril devido ao deslizamento de parte da via, além das atividades de uma pedreira localizada a poucos metros do bairro. Para facilitar a compreensão, utilizaremos o grifo em itálico para diferenciar os textos das matérias do texto analítico.

\footnotetext{
${ }^{4}$ Reportagem disponível no canal do YouTube da TV Feevale em: http://www.youtube.com/tvfeevale\#p/search/0/kncmiKQny2w, acesso em 20/07/2011.
} 
Repórter: Um paraíso verde dentro de Novo Hamburgo: o bairro Alpes do Vale fica há 7 minutos do centro da cidade. Mas toda essa tranquilidade foi abalada ano passado, quando a pedreira voltou suas atividades" e em "os abalos consequentes das detonações, além de medo, estão causando outros transtornos"

A utilização das palavras "paraíso", "tranquilidade" e "medo", usadas no texto de apresentação da repórter, repetem as palavras citadas nas sonoras feitas junto aos moradores. É como se a repórter legitimasse a queixa dos moradores do bairro e se colocasse a seu favor. Notaram-se, portanto, uma proximidade e identificação entre repórter e fonte, além de ter sido percebida a "vontade" de falar dos habitantes do local, que somaram ao todo quatro depoimentos, sendo que todos possuíram mais de 30 segundos.

Na primeira sonora, o morador do bairro Claudio Petry diz:

Fonte: A gente tá tentando se mobilizar através da associação para ver se a prefeitura nos ouve, nos enxerga aqui em cima, por que tudo bem a a gente sabe que eles nos veem como a minoria, mas nós não somos a burguesia, todos nós pagamos impostos aqui em cima a gente quer o que é de direito, o de ir e vir para a nossa casa.

Outra sonora que demonstra essa falta de atenção do poder público é a do presidente da associação de moradores:

Fonte: Toda que fez que existe a necessidade do poder público, esse apoio pára ele é estanque, então tudo que se consegue é através de eventos (...) as 82 famílias arrecadam mais de 120 mil de imposto, mas o retorno é zero.

Ao todo, nessa reportagem, foram seis sonoras, sendo quatro com moradores do local e duas com responsáveis da prefeitura da cidade. O teor das falas das sonoras da comunidade, mais uma vez, deixa evidente o espaço que o telejornal permite a eles. Em geral, é o momento da reclamação, da fala direta ao prefeito da cidade, uma linha direta que possa colaborar com a resolução do problema.

Mas além de escutar a comunidade, o TV Feevale Notícias, na mesma edição, fez uma entrevista em estúdio com o Procurador Geral de Novo Hamburgo Reginaldo Parnoff ${ }^{5}$. Antes de iniciar a entrevista, ainda é mostrada outra matéria feita no bairro sobre o encaminhamento dos documentos feito pela associação comunitária do bairro Alpes do Vale sobre a retirada de casas construídas ilegalmente em áreas públicas. É apresentada a fala do presidente da associação, que exige da prefeitura uma resposta sobre o assunto. Outra moradora é ouvida e reclama da invasão da praça do bairro. Ela

\footnotetext{
${ }^{5}$ Disponível no canal do YouTube da TV Feevale em: http://www.youtube.com/tvfeevale\#p/search/1/Kilgk6Mwc0E, acesso em 20/07/2011.
} 
termina sua fala com: "eu já pedi então que eles (secretários da prefeitura) venham ver a realidade da nossa praça, só que até agora eles não se manifestaram”. Assim que é concluída a reportagem, o apresentador do telejornal aparece no estúdio com o procurador geral de Novo Hamburgo .

Essa estratégia de mostrar ao vivo a reportagem para o procurador demonstra o posicionamento do telejornal e faz com que o representante da prefeitura enfrente as reclamações e tenha a obrigação de dar uma resposta aos moradores do bairro Alpes do Vale. No entanto, notamos a preocupação do telejornal em dar espaço tanto para a comunidade, através das duas matérias veiculadas em uma mesma edição, somando ao todo nove minutos e trinta segundos, possibilitando às várias vozes da comunidade expor os problemas enfrentados, quanto para o procurador da prefeitura, que concedeu uma entrevista de aproximadamente 10 minutos. Percebemos a tentativa do apresentador em buscar um retorno às questões levantadas pelos moradores nas reportagens.

O apresentador diz: "Nós vimos vários problemas localizados ali no bairro Altos do Vale, nós conversamos com o secretário Farias, com o secretário da secretaria de urbanismo, o senhor Lino, para tentar resolver e entender o que está acontecendo, a tua presença aqui é para entender essa questão das invasões. Os moradores já encaminharam solicitações na prefeitura desde outubro de 2010 (..) eu quero saber do senhor como essas solicitações têm chegado até a prefeitura, tendo em vista que os moradores não estão recebendo retorno por parte do município."

Mesmo tendo uma fala incisiva e direta voltada ao procurador, o apresentador não recebe uma resposta direta, e sim explicações baseadas em números de obras feitas pela prefeitura. Por isso, ao final da entrevista, mais um vez o apresentador se coloca ao lado da comunidade e diz: " antes de encerrar a entrevista, os moradores também reclamam da falta de atenção do poder público, da presença do poder público lá para tentar achar uma solução para esses (..) o secretário de transporte já esteve no local e liberou a verba, mas os moradores entendem que demora para liberar(..) mas essa reclamação sobre o poder público e essa falta de resposta, falando agora bem direcionado aos moradores, que tipo de resposta eles podem esperar para as próximas semanas vindo como resposta a essas demandas deles?".

A partir da fala acima, mais uma vez é verificada a tentativa do apresentador de conseguir uma solução ou uma explicação sobre o descaso e a falta de respostas por parte da prefeitura. Essa solicitação do apresentador demonstra que o procurador não respondeu durante os seus quase dez minutos de entrevista às reclamações da comuni- 
dade, porém fica marcada a vontade e o interesse do apresentador em conseguir ter uma resposta sobre os problemas do bairro.

\section{CONSIDERAÇÕES: APROXIMAÇÕES ENTRE TELEJORNALISMO REGIONAL E TVS UNIVERSITÁRIAS}

Nessa breve exposição foi possível visualizar uma relação muito forte e promissora entre os objetivos do telejornalismo regional, que encontram fortes aliadas nas TVs universitárias devido às suas características voltadas à educação e ao compromisso com a comunidade em que estão inseridas.

No caso específico analisado, a TV Feevale, por intermédio do TV Feevale Notícias, conseguimos verificar que a TV universitária não tem somente como objetivo principal divulgar os acontecimentos acadêmicos ou servir de laboratório para futuros comunicólogos, mas poder ser porta-voz da comunidade, colaborar com o "viver junto", priorizando em seus programas os assuntos pertinentes à localidade da qual faz parte, conseguindo assim credibilidade da população.

O compromisso das televisões universitárias é aprofundar o conteúdo, repassar uma informação de qualidade, algo nem sempre encontrado na televisão aberta devido às regras políticas e mercadológicas. Ao assistir ao telejornal, vimos falas de cidadãos que citam abertamente o seu descontentamento com o prefeito, com os secretários etc. Citações que geralmente são editadas em telejornais pertencentes às grandes corporações do estado.

Por intermédio dos dados quantitativos e qualitativos, foi verificado que o telejornal diário da TV Feevale e suas reportagens comunitárias, mostram esse processo de afeto entre repórter e fonte. A afetividade exposta nas matérias demonstra a necessidade do viver junto, mas não interfere nos critérios de noticiabilidade. $\mathrm{O}$ afeto percebido na fala dos repórteres que aconselham, deixam a fonte expor suas reclamações, é visto como elemento essencial na busca das informações e colabora para a relação mais amistosa com as fontes, que ligam para a redação do telejornal indicando pautas.

Nesse sentido, entendemos que essa relação é delicada, porém necessária, pois é preciso estar sempre atento às mudanças de comportamento e compreender de que forma elas influenciam na construção das notícias que têm sido apresentadas para o público. Essa tendência na televisão foi inaugurada pelo programa Profissão Repórter, coordenado pelo jornalista Caco Barcellos, que além de aprofundar temáticas nas repor- 
tagens, também mostra os sentimentos, as dúvidas e angústias dos repórteres na apuração da notícia.

Assim fica em aberto o debate sobre a construção da notícia quando ocorre o envolvimento do repórter com as fontes em televisões voltadas a comunidades menores. Por enquanto ainda não temos respostas. Somente a partir da observação e análise de produtos jornalísticos televisivos e com o retorno da sociedade é que conseguiremos verificar se este novo caminho irá cooperar ou ainda influenciar a qualidade do Jornalismo contemporâneo.

\section{REFERÊNCIAS}

BARTHES, Roland. Como viver junto: simulações romanescas de alguns espaços cotidianos.São Paulo: Martins Fontes, 2003.

BAZI, Rogério Eduardo Rodrigues. TV regional: trajetórias e perspectivas. Campinas, SP: Editora Alínea, 2001

BERGESH, Walmor. Os Televisionários. Porto Alegre: Ardotempo, 2010.

BOURDIN, Alain. A Questão Local. Rio de Janeiro: DP\&A, 2001.

COUTINHO, Iluska. Telejornalismo e identidade em emissoras locais: a construção de contratos de pertencimento (p. 91-107). In:A sociedade do Telejornalismo. Petrópolis, RJ: Vozes, 2008.

LAGE, Nilson. A reportagem: teoria e técnica de entrevista e pesquisa jornalística. Rio de Janeiro: Record, 2001

MAGALHÃES, Cláudio. Manual para uma TV Universitária. Belo Horizonte: Ed. Autêntica, 2002;

PUHL, Paula Regina. O viver junto no Programa Profissão Repórter: o afeto na Construção da Reportagem Televisiva. Rio de Janeiro: Revista Eco-Pós,Vol 13, n.2, 2010. Acesso disponível em: http://www.pos.eco.ufrj.br/ojs-2.2.2/index.php/revista/article/view/325/0

RAMALHO, Alzimar Rodrigues. O perfil da TV universitária e uma proposta de programação interativa. Disponível em < http://www.teses.usp.br>. Acesso em junho 2011.

TEIXEIRA, Rodrigo. História da TV Feevale. Novo Hamburgo, 02 jun. 2011. Entrevista concedida a Aline Streck Donato.

TV universitária: uma televisão diferente. Disponível em: $<$ http://www.abtu.org.br $>$. Acesso em maio 2011;

UNESCO, Pesquisa: A TV Universitária no Brasil. Unesco, 2004. Disponível em $<$ Www.unesco.org.br>. Acesso em junho 2011;

VIZEU, Alfredo. Decidindo o que é notícia: os bastidores do telejornalismo. Porto Alegre: EDIPUCRS, 2005. 
Original submetido em: 26/03/2013

Aprovado para publicação em: 20/05/2014

Sobre a autora

Paula Puhl

Graduada em Comunicação Comunicação Social Jornalismo pela Pontifícia Universidade Católica do Rio Grande do Sul (1998), mestrado (2001) e doutorado (2003) na mesma instituição. Professora do Curso de Comunicação Social e no Curso Superior de Tecnologia em Produção Audiovisual na Pontifícia Universidade Católica do Rio Grande do Sul. É lider do projeto de pesquisa: A construção das identidades pelo Telejornalismo local: mapeamento e análise", aprovado pela $\mathrm{Fa}-$ pergs - Pesquisador Gaúcho. É diretora Regional Sul da INTERCOM - Sociedade Brasileira de Estudos Interdisciplinares da Comunicação e pertence ao GIPTELE - Grupo Interinstitucional de Pesquisa em Telejornalismo. 